\title{
Key Algorithms And Its Realization About Snowmelt Flood Disaster Model Based On Remote Sensing And GIS
}

\author{
Chen Qiao ${ }^{1, *}$, Quanyi Huang ${ }^{1}$, Tao Chen ${ }^{1}$, and Zhipeng $\mathrm{Li}^{2}$ \\ ${ }^{1}$ Tsinghua University, Department of Science and Technology on Public Safety, 100084 Hai Dian, Beijing, China \\ ${ }^{2}$ Beijing Global Safety Technology Co. Ltd., 100094 Hai Dian, Beijing, China
}

\begin{abstract}
Based on the remote sensing and GIS techniques, the relationships of the variables influencing the snowmelt flood such as the snow area, the snow depth, the air temperature, the precipitation, the land topography and land covers are analyzed and a prediction and damage assessment model for snowmelt floods is developed. This model analyzes and predicts the flood submerging range, flood depth, flood grade, and the damages of different underlying surfaces in the study area in a given time period based on the estimation of snowmelt amount, the snowmelt runoff, the direction and velocity of the flood. Then it was used to predict a snowmelt flood event in the Ertis River Basin in northern Xinjiang, China, during March and June, 2017 and to assess its damages including the damages of roads, transmission lines, settlements caused by the floods and the possible landslides using the hydrological and meteorological data, snow parameter data, DEM data and land use data. A comparison was made between the prediction results from this model and flood measurement and its disaster loss data, which suggests that this model performs well in predicting the strength and impact area of snowmelt flood and its damage assessment.
\end{abstract}

\section{Introduction}

Snowmelt water is an important fresh water resource in mid-high latitudes and mountainous areas, but it could cause great disasters to the local area in the form of flood under certain conditions. During the melting period, the sharp rise in temperature will accelerate the melting of snow, leading to spring floods, washing away farmland, impeding traffic and endangering people's lives and property. Especially in the context of global warming, the occurrence rate of snowmelt floods in arid and semiarid mountainous areas of middle and high latitudes is increasing, causing serious casualties and property losses. Therefore, it is of great significance to carry out monitoring and risk assessment of snowmelt flood, and to establish accurate and effective snowmelt flood disaster model for optimal water resources management, flood early warning and disaster prevention and reduction.

According to the principle, the simulation and prediction of snowmelt runoff can be generally divided into two types: statistical model based on meteorological factors and energy balance model based on physical mechanism. The former can also be divided into simple temperature index method, degree-day factor method [1] and modified degree-day factor method, which mainly takes temperature as the reference standard of snowmelt, or is modified by meteorological factors, such as wind speed and radiation, etc. This method has been applied in SRM and SWAT snowmelt computing module. The statistical model based on meteorological factors has the advantages of simple structure, less input parameters and easy access. It is widely used at home and abroad. But this model has certain limitations and is not easy to be popularized in space. The energy balance method is mainly based on the physical process of melting snow, which has strict physical significance and can make relatively accurate simulation and forecast of melting snow. This method has been studied early in foreign countries, and some representative snowmelt models have emerged, such as SNOBAL and UEB [2-3]. Based on these studies, the energy balance model based on physical mechanism has also developed from a single point format to a distributed one [4-8]. The research on snowmelt flood model in China started late, mainly focusing on the application research of existing models.

Based on remote sensing and GIS technology, this study takes snow area, snow depth, density, soil, topography, climate and land cover types as the main factors influencing of snowmelt floods, comprehensive analysis of the relationship between various influencing factors of snowmelt flood prediction and evaluation model is established. The model based on the regional amount of snowmelt, snowmelt production flow, the calculation of flow, velocity and so on, analysis and forecast the flooding of the area within a certain time, flood depth, flood level and different underlaying surface damage in the study area. This model will be helpful for the prediction and damage assessment of snowmelt flood events in the mountainous area in the middle and high latitudes in spring, which has great social and economic significance because it provides a relatively reliable

\footnotetext{
* Corresponding author: qiaochen@tsinghua.edu.cn
} 
method for snowmelt flood prediction and reduces the possible damages caused by snowmelt floods.

\section{Methods}

Snowmelt floods are mainly distributed in high latitudes or mountainous areas at high altitudes and occur in spring and summer. The main factors influencing the size and process of snow flood are: the area of snow cover, depth of snow, density of snow, water holding capacity, heat of snow melting, and the topography, landform, orientation, climate and land use of snow covered areas, which have cross influences on each other. The model is highly coupled with RS and GIS technology by means of grid scale snowmelt flood. The models include: raster melting snow volume calculation, raster production flow calculation, flow matrix calculation, flow rate matrix calculation, flow distribution of river basin, flood inundation range prediction and disaster situation prediction of underlying surface.

\subsection{Calculation of snowmelt volume}

The image data of snow water equivalent represents the amount of water that can be produced by the total melting of snow cover. The difference value between the two images of snow water equivalent is the amount of water produced by the melted snow in this period, namely the amount of snow melt.

The snow water equivalent images data based on remote sensing were obtained by the calculation of MODIS data. The formula for calculating the daily average raster melting snow volume is as follows:

$$
Q_{\text {melt }}=\frac{M_{1}-M_{2}}{D_{0}}
$$

Where $M_{l}$ is the equivalent of snow water in the previous stage, and the unit is $\mathrm{mm}, M_{2}$ is the equivalent of snow water in the later stage, and the unit is $\mathrm{mm}, D_{0}$ is the time resolution of remote sensing data, and the unit is $\mathrm{d}, Q_{\text {melt }}$ is the daily snow melt quantity in $\mathrm{mm} / \mathrm{d}$ during this period.

\subsection{Calculation of flow generation}

The melting of frozen soil is usually later than the melting period of snow cover. At this time, the seepage capacity of melting snow is small, and the main form is hypertonic flow. When the air temperature rises and the thawing layer of frozen soil becomes thicker, the melting snow speed becomes faster. At this time, the infiltration of melting snow water increases, that is, the storage full production flow is increased, and the production flow is the full production flow and hypertonic production flow. Therefore, the amount of snow melt is not equal to the amount of grid water.

The calculation of infiltration between snow melt water and frozen soil is based on the green-ampt model method proposed by Green and Ampt et al. [9]:

$$
i_{W}=K_{s}\left(\frac{Z_{W}+h_{0}+\psi_{W}}{Z_{W}}\right)
$$

Where $i_{w}$ is infiltration rate, $K_{s}$ is the saturated permeability coefficient, and $Z_{W}$ is the depth of the wet front at time $\mathrm{t}$ (Angle mark " $W$ " stands for the wet front), $h_{0}$ is the hydrated head at the surface, $\Psi_{W}$ is the average matrix suction head of wetting front, it is a function of water content, which can be calculated by experiment or soil water content [10]. The spatial distribution of soil moisture content in this paper was determined by NCEP reanalysis data, but the accuracy of the soil moisture content was not improved due to the influence of snow cover.

Based on the above, the calculation formula of snowmelt flow is:

$$
Q_{\text {flow }}=\left(Q_{\text {melt }}+Q_{\text {rainfall }}\right) \times\left(1-i_{W}\right)
$$

Where $Q_{\text {melt }}$ is the amount of melting snow at the calculation time, and the unit is $\mathrm{mm} / \mathrm{h}, Q_{\text {rainfall }}$ is the amount of precipitation at the time of calculation, and the unit is $\mathrm{mm} / \mathrm{h}, i_{w}$ is infiltration rate, $Q_{\text {flow }}$ is the production flow at the calculation time in $\mathrm{mm} / \mathrm{h}$.

\subsection{Calculation of confluence}

The model adopts the principle of equal flow time line in grid confluence, that is, when calculating the hysteresis between each unit and outlet in the basin, all units are superimposed at the outlet to calculate the outflow at the moment of unit.

\subsubsection{Flow matrix calculation}

DEM pretreatment is to transform the depressions and small flatlands in the data into slopes, that is, the topographic features reflected in the DEM data are composed of slopes. Such treatment can enable water flow to flow out of the watershed boundary according to the surface runoff model. The pretreatment process mainly includes depression calibration and uplift treatment, i.e., filling and leveling treatment.

Based on watershed without concave points and flat area of DEM data, we use D8 algorithm to determine the flow direction of a grid, and compare the slope drop between the treated grid and the nearest 8 grids. The direction of the connection between the center of the treated grid and the center of the largest grid on the slope is defined as the flow direction of the treated grid. The direction of water flow in the specified grid is represented by the characteristic code, and the effective direction of water flow is defined as northeast, east, southeast, south, southwest, west, northwest and north, respectively, with $128,1,2,4,8,16,32$ and 64 .

\begin{tabular}{|c|c|c|}
\hline 32 & 64 & 128 \\
\hline 16 & $(\mathrm{i}, \mathrm{j})$ & 1 \\
\hline 8 & 4 & 2 \\
\hline
\end{tabular}

Fig. 1. The direction of D8 algorithm. 
For all the grids at the edge, the directional value pointing to the edge is assigned, and the flow direction on the boundary is not changed in subsequent processing. This is done to facilitate the processing of the boundary flow direction without any negative impact.

\subsubsection{Calculation of confluence accumulation}

The confluence accumulation is calculated based on the flow direction data. For each grid, the magnitude of its confluence accumulation represents the number of grids upstream of which the direction of water flow finally passes through the grid. The greater the value of confluence accumulation, the easier it is for the region to form surface runoff.

\begin{tabular}{|c|c|c|}
\hline 4 & 2 & 4 \\
\hline 1 & 2 & 4 \\
\hline 128 & 1 & $?$ \\
\hline
\end{tabular}

\begin{tabular}{|l|l|l|}
\hline 0 & 0 & 0 \\
\hline 2 & 3 & 2 \\
\hline 0 & 0 & 8 \\
\hline
\end{tabular}

Fig. 2. The calculation method of the accumulation of confluence.

According to the natural law of water flowing from high to low, the number of grids flowing through each grid in the region is calculated according to the data of water flow direction as the cumulative value of the confluence.

\subsubsection{Velocity matrix calculation}

The distributed flow rate matrix is an important part of the convergence model. The flow velocity in the snowmelt area is mainly divided into slope convergence and river convergence. First, slope convergence and river convergence are distinguished by the threshold value of grid water collection area. For the grid outside the channel, it accumulates to the channel according to the slope convergence, and then calculates according to the channel convergence evolution. The velocity of nonriver area mainly comes from the conversion of gravitational potential energy into kinetic energy.Data is obtained by observation, measurement or other historical evidence.

The kinetic energy of snowmelt water mainly comes from the difference between the conversion of gravitational potential energy and the ground resistance loss. The obtained kinetic energy is related to ground vegetation, roughness, slope, water flow path, etc. The model uses manning's formula [11] to calculate the water velocity. It is assumed that the kinetic energy before melting snow is 0 and the water depth is 0.The formula for calculating the velocity is:

$$
V=\frac{1}{\mathrm{n}} R^{\frac{2}{3}} S^{\frac{1}{2}}
$$

Where $V$ is the velocity of snowmelt water on the slope before it flows into the channel, and the unit is $\mathrm{m} / \mathrm{s}$, $R$ is the hydraulic radius, which is the ratio of fluid cross section area to wet circumference. Wet perimeter refers to the perimeter of the fluid in contact with the open channel section, excluding the perimeter of the fluid in contact with the air. In practice, the average depth $H$ of the section is often used instead of the hydraulic radius $R$. $N$ is the roughness of river course, $S$ is the slope.

\section{Model application}

\subsection{Study area}

The Ertis River Basin (within China) is located in northern Altay region, Xinjiang Autonomous Region. From the Altai Mountains on the southern slope of the It has braches such as Haba River, Burqin River, Crane River, Kala Erqi River which locates in the south slope of Mt. Altay. The Ertis River flows from east to west of the basin, then goes north to the Arctic Ocean. The basin area of $5.729 \times 10^{4} \mathrm{~km}^{2}$.

Floods in this basin generally occur from the end of May to the middle of June. Seasonal snowmelt floods account for $50 \%$ of the annual maximum floods of major rivers in the basin, and the seasonal snowfall and rainfall mixed floods account for $32 \%$ 。 These facts suggest that floods occur frequently and the influence is important.

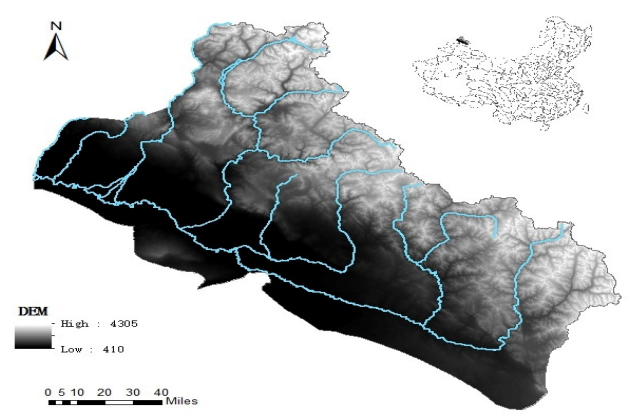

Fig. 3. The location of the erzias river basin.

\subsection{Data acquisition and processing}

\subsubsection{DEM data}

The DEM data used in this study is SRTM data with a resolution of $90 \mathrm{~m}$. First, DEM preprocessing is carried out to reduce the errors of flow direction in flat areas and no flow out in low-lying areas. According to the actual situation of the study area, the impact can be reduced by the calculation and filling of elevation increment, and the preprocessed DEM data can be analyzed by ARCGIS to analyze the flow direction, convergence accumulation, river network and sub-watershed, etc.

\subsubsection{Basic data}

The basic data include administrative division data from China's basic geographic information vector atlas, watershed range, river system and other data from the national river division data set, as well as population, watershed area, roads, transmission lines and residential areas. 


\subsubsection{Meteorological data}

The meteorological data required for the model comes from the NCEP reanalysis data. The model validation and prediction of snowmelt flood were carried out with temperature data. As the main input parameter of the model, the rainfall data are used to calculate the total runoff.

\subsubsection{Remote sensing data}

According to the model, the snow cover, snow depth and snow water equivalent data of spring 2017 in northern xinjiang obtained from the calculation and processing of MODIS data were selected, with a time resolution of 5 days and a data resolution of $500 \mathrm{~m}$. Snow cover distribution data are used for spatial analysis of snow cover area and snow cover rate. Snow depth is a sensitive factor in regional response to climate change, which can be combined with meteorological data to predict snowmelt volume. The equivalent snow water data are used to calculate the daily snowmelt volume and production flow in the drainage area. Combined with rainfall and evaporation infiltration, the runoff velocity is obtained to analyze the spatial and temporal changes of the flood coverage and the disaster impact.

\subsection{Results analysis}

\subsubsection{Snow cover change analysis}

Snow cover is a layer of snow covering land and sea ice.Snow cover distribution data are used for spatial and temporal analysis of snow cover area and snow cover rate. In this study, the spatial and temporal analysis of snow cover area and snow cover was carried out using the snow cover distribution data from March 1 to June 4, 2017 in the ertis river basin. It indicates that the snowmelt started on March 26 and the snow melted at a high rate until mid-to-late April when strong snow in the whole Xinjiang occurred. The snow melt in Xinjiang had slowed down and even increased, to around $40 \%$. The snow in the study area started to melt in May due to the fast increase of air temperature, and it lasted until the early June when the seasonal snowmelt process ends.

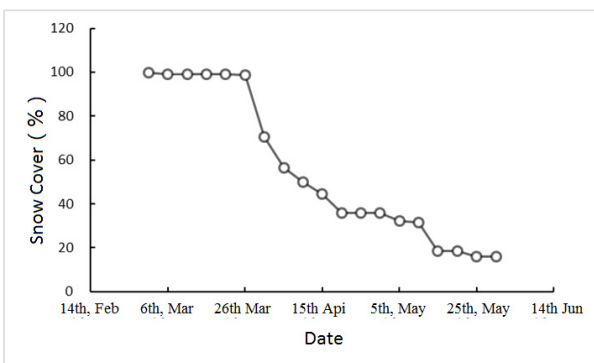

Fig. 4. Snow cover changes in spring 2017 in the study area.

\subsubsection{Depth of snowmelt runoff}

With the data of the hydro meteorological, the accumulated snow, DEM and land use of the ertis river basin from May 4 to May 9, the snowmelt runoff process was analyzed by using the snowmelt flood model established in this study, and the snowmelt runoff and water depth were obtained.

As shown in figure 5, the northern part of Xinjiang is the region most prone to flooding in spring in terms of spatial distribution. The Qinghe area, Altay city and Burqin county is the area where the flood occurs most frequently. Moreover, Fuyun county and Habahe county also experienced snowmelt floods. This is consistent with the flood characteristics described in many literatures in Xinjiang [12]. From the historical data of flood flow, the annual average value of flood peak in Altay region is $0 \sim 550 \mathrm{~m}^{3} / \mathrm{s}$, which is consistent with the flow range of typical areas from our model.

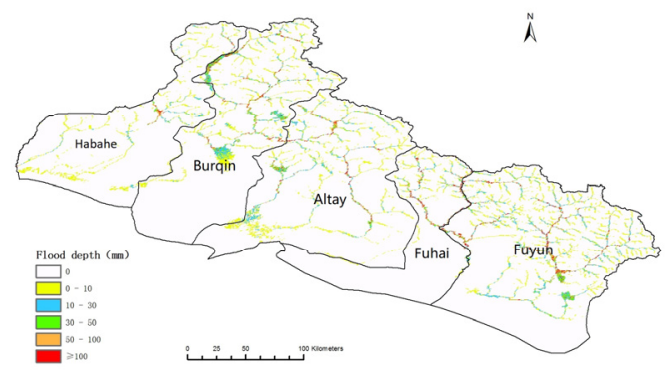

Fig. 5. The depth of snowmelt runoff on May 9 of the study area.

Based on the prediction of snowmelt flow, water depth, the residence area, industrial area and the threshold data for the flood warning of the study area, the possible area and the people which are impacted by the snowmelt flood are analyzed. The corresponding measures including the people evacuation and resettlement, resources for these people are also analyzed, which will be very helpful for local government in the decision-making.

\section{Conclusions}

In this study, a model for the snowmelt flood and disaster assessment was constructed based on remote sensing coupled with NCEP meteorological reanalysis data under the support of "3S" technology. Based on the grid-scale snow melting parameters, this model calculates the snowmelt amount and flow rate and forecasts the runoff within a certain period of time, and predicts the range, depth and severity of flood. With the remote sensing, this study provides a method for forecasting snowmelt runoff in the area in the middle and high latitudes where the unevenly distributed snow is difficult to observe in the mountainous area.

The prediction of snowmelt runoff based on snowmelt runoff model can provide a reference results for snowmelt flood forecasting and water resources management. The model is based on the physical mechanism and does not require years of routine observation data, so the applicability is wide and effective. 


\section{Acknowledgments}

The authors appreciate the Project 2017YFC0803300 and 2017YFC1405304 support by MOST, and the project Z161100001116010 supported by Beijing Municipal Science \& Technology Commission.

\section{References}

1. S. Finsterwalder, Der suldenferner. Zeitschrift des Deutschen und Osterreichischen Alpenvereins, 18, 72-89 (1887)

2. D. Marks, J. Domingo, D. Susong, et al., A spatially distributed energy balance snowmelt model for application in mountain basins. Hydrological Processes, 13, 1935-1959 (1999)

3. T. H. R. Jackson, A spatially distributed snowmeltdriven hydrologic model applied to the upper Sheep Creek watershed, (1995)

4. X. Liang, E. F. Wood, D. P. Lettenmaier, Surface soil moisture parameterization of the VIC-2L model: Evaluation and modification. Global and Planetary Change, 13, 195-206 (1996)

5. J. P. Evans, Improving the characteristics of streamflow modeled by regional climate models. Journal of Hydrology, 284, 211-227 (2003)

6. G. Y. Niu, Z. L. Yang, Effects of frozen soil on snowmelt runoff and soil water storage at a continental scale. Journal of Hydrometeorology, 7, 937-952 (2006)

7. D. Bewley, R. Essery, J. Pomeroy, et al., Measurements and modelling of snowmelt and turbulent heat fluxes over shrub tundra. Hydrology and Earth System Sciences, 14, 1331(2010)

8. L. S. Kuchment, P. Romanov, A. N. Gelfan, et al., Use of satellite-derived data for characterization of snow cover and simulation of snowmelt runoff through a distributed physically based model of runoff generation. Hydrology and Earth System Sciences, 14, 339-350(2010)

9. W. H. Green, G. A. Ampt, Studies on Soil Phyics, The Journal of Agricultural Science, 4, 1-24 (1911)

10. R. G. Mein, D. A. Farrell. Determination of wetting front suction in the Green-Ampt equation, Soil Science Society of America Journal, 38, 872-876 (1974)

11. R. Manning, J. P. Griffith, T. F. Pigot, et al., On the flow of water in open channels and pipes, (1890)

12. A. Ablikim, C. Chunyan, Y. Abdula, et al., The temporal and spatial distribution features of snowmelt flood events in Xinjiang from 2001 to 2012, Journal of Glaciology \& Geocryology, 37, 226-232 (2015) 